\title{
Expectativas profissionais e percepções dos concluintes: formação e atuação de pedagogos nos espaços não escolares
}

\section{Professional expectations and perceptions of the concluintes: training and performance of pedagogues in non-school spaces}

\author{
Luciana Silva Dias ${ }^{1}$ \\ Douglas Pereira da Costa ${ }^{2}$ \\ Maria das Dôres de Sousa ${ }^{3}$
}

\section{Resumo}

As questões abordadas neste trabalho pretendem contribuir com o debate em torno das expectativas profissionais e das percepções dos concluintes do curso de Pedagogia participantes da pesquisa sobre a formação e atuação de pedagogos em espaços não escolares. Deste modo, propôs-se verificar as possibilidades que o curso de pedagogia apresenta para a formação de pedagogos em espaços não escolares. Os resultados apresentados foram obtidos por meio de uma metodologia de pesquisa de abordagem qualitativa. Para a coleta dos dados, aplicou-se um questionário estruturado junto a 20 graduandos do décimo bloco do curso de Pedagogia. Para exame dos dados coletados, recorreu-se à Análise de Conteúdo em Bardin (2011). Os resultados apontam que os concluintes reconhecem demandas para atuação do pedagogo em espaços não escolares, mas o curso tem como base a docência na Educação Infantil e nos Anos Iniciais do Ensino Fundamental. Os alunos citaram algumas experiências vivenciadas no decorrer do curso em espaços não escolares. Porém, ressaltaram que sentiram falta de estudos com abordagens relativas aos conhecimentos teóricos e metodológicos para fundamentação de suas ações nesses ambientes. Portanto, é importante que o curso de Pedagogia proporcione uma formação mais completa e sólida, que possibilite uma ressignificação da construção da identidade profissional dos pedagogos para além da sala de aula.

Palavras-chave: Curso de Pedagogia; Pedagogia; Campo de atuação.
Abstract
The issues addressed in this work intend to contribute to the debate around professional expectations and perceptions of the graduates of the Pedagogy course participating in the

\footnotetext{
${ }^{1}$ Mestre em Educação, Universidade Federal da Paraíba, João Pessoa, Paraíba, Brasil. Email lucianadiasibn@gmail.com

${ }^{2}$ Mestre em Educação, Logos University International, Miami, Flórida, EUA. Email douglascostapedagogo@hotmail.com

${ }^{3}$ Doutora em Educação, Universidade Federal do Piauí, Picos, Piauí, Brasil. Email mariadasdoressousa@hotmail.com
} 
research on the training and performance of educators in non-school spaces. Thus, it was proposed to verify the possibilities that the pedagogy course presents for the training of pedagogues in non-school spaces. The results presented were obtained through a qualitative research methodology. For data collection, a structured questionnaire was applied to 20 undergraduate students in the tenth block of the Pedagogy course. To examine the data collected, we used Content Analysis in Bardin (2011). The results show that the graduates recognize demands for the pedagogue's performance in non-school spaces, but the course is based on teaching in Early Childhood Education and in the Early Years of Elementary Education. The students mentioned some experiences they had during the course in nonschool spaces. However, they stressed that they felt the lack of studies with approaches related to theoretical and methodological knowledge to justify their actions in these environments. Therefore, it is important that the Pedagogy course provides a more complete and solid training, which allows a new meaning in the construction of the pedagogical professional identity beyond the classroom.

Keywords: Pedagogy Course; Pedagogy; Field of activity.

\section{Introdução}

A motivação para a realização dessa pesquisa tem sua origem no confronto entre as expectativas da pesquisadora antes de optar por cursar Pedagogia e a experiência dela ao longo do processo formativo, o que a instigou a refletir sobre as expectativas dos concluintes e como tais expectativas se convertem em escolhas e engajamentos formativos dos sujeitos diante das possibilidades que a profissão de pedagogo oferece.

Observa-se que muitos estudantes possuem expectativas de formação em relação ao curso de Pedagogia que não se associam diretamente à formação docente para o exercício do magistério na Educação Infantil e nos Anos Iniciais do Ensino Fundamental. A experiência da pesquisadora enquanto graduanda do curso serve para ilustrar como a escolha pelo curso de Pedagogia é fruto do anseio de pessoas que se interessam em atuar em um contexto educacional amplo e não necessariamente nas instituições escolares.

As Diretrizes Curriculares Nacionais do Curso de Pedagogia preconizam a inclusão dos espaços não escolares para a atuação do pedagogo (BRASIL, 2006). Todavia, não é clara a maneira como este profissional vai ser formado e os princípios de atuação nesses diferentes espaços. O desafio é pensar um currículo que desenvolva competências para os pedagogos atuarem nesses contextos educativos diversos que necessitam de práticas pedagógicas específicas, consequentemente, esses novos campos de atuação influenciam na (re)construção 
da identidade do pedagogo.

\begin{abstract}
A respeito da construção da identidade do pedagogo, cremos que é o processo de formação continuada, e não apenas a formação à que a legislação obriga, que vem se constituindo como um locus privilegiado, no qual os saberes se entrelaçam e ganham significação. O pedagogo necessita ser um profissional mutante, capaz de vislumbrar diferentes formas de atuação, de acordo com o contexto no qual está inserido (SCHIMITZ, 2013, p. 19).
\end{abstract}

É nesse processo de atendimento às novas demandas que a Pedagogia e a identidade desse profissional ressignificam-se, perpassando por transições conceituais de campo e criando novos sentidos a fim de ampliar as formas do fazer pedagógico para além da escolarização.

Sabe-se que o curso de Pedagogia deve acompanhar o processo educacional em sua globalidade, proporcionando aos graduandos intervenções nas instâncias escolares e não escolares. Porquanto, a educação nesses espaços educativos diversos requer uma sistematização; não se pode apostar em práticas espontâneas e assistemáticas. Por isso, precisa-se de uma Ciência da Educação que seja engajada, mantenedora de uma relação indissociável entre teoria e prática, que assuma seu objeto de estudo que é o fenômeno educativo na sua globalidade (FRANCO, 2008).

Compreende-se o não escolar não em negação à escola, mas como possibilidade de ampliar as práticas educativas para outros espaços. O conceito de não escolar, como especifica Severo (2015), não pode ser reduzido à categoria de educação não formal, considerando a existência dos processos de formalização e de intencionalidade, muito embora estes sejam diferentes dos existentes no âmbito escolar que se pautam em marcos normativos e estratégicos de natureza educativa. Desse modo, defende-se a ressignificação da compreensão da Educação Não Formal para Educação Não Escolar (ENE), possibilitando a visualização de componentes pedagógicos baseados em métodos e estratégias com distintos graus de formalidade, pautados nas políticas específicas de cada atividade.

A Pedagogia como a Ciência da Educação deve abranger diferentes fenômenos (educação formal, educação não escolar e informal), uma vez que, o processo educativo é amplo e social, extrapola o contexto escolar e dá-se em diferentes espaços porque "todos os 
outros espaços, além da escola, produzem influências formativas sobre sujeitos, produzem saberes, propõem comportamentos e valores, estimulam ações e pensamentos" (FRANCO, 2008, p. 80). No entanto, essas ações devem ser conduzidas por profissionais preparados por uma Ciência da Educação que tenha uma formação teórica sólida e crítica das práticas educativas escolares e não escolares. Não se pode limitar a pedagogia apenas à docência, pois esta é apenas uma de suas práticas.

Libâneo (2002, p. 67) comenta que "a docência subordina-se à pedagogia, uma vez que o ensino é um tipo de prática educativa". Partindo desse entendimento, se a Pedagogia é resumida à docência escolar, acaba restrita a uma simples metodologia ou tecnologia de ensino. Assim, a concepção de Pedagogia fica resumida apenas a um dos seus fenômenos educativos, qual seja a educação formal, e acaba perdendo a finalidade da Ciência da Educação, que, por sua vez, deve estar comprometida em estudar a educação no seu sentido global.

Por esse motivo, há necessidade da Pedagogia constituir-se como "um novo paradigma de ciência que incorpora princípios de complexidade, da reflexidade, da comunicação simbólica e intersubjetividade como elementos fundantes da matriz epistemologica" (SEVERO, 2012, p. 68), uma vez que os processos educacionais estão cada vez mais complexos e demandam uma ciência que transforme essa complexidade, pois, as novas tecnologias adentraram o âmbito educacional e a função educativa não se limita apenas ao espaço escolar.

Os cursos de Pedagogia precisam analisar e refletir sobre as práticas educativas desenvolvidas, se estão acontecendo de maneira social, ou se estas práticas se voltam somente para a intervenção dos sujeitos na escola, esquecendo-se do seu papel social, pois, como afirma Saviani (2008), é por meio das práticas educativas que o educando chegará a um determinado fim. É necessário rever a trajetória histórica e teórica da Pedagogia ou Ciência da Educação para ser alcançado um consenso quanto a sua concepção.

Severo (2015), Pimenta (2011) e Libâneo (2002; 2005) problematizam os limites da concepção da docência como base formativa nos currículos dos Cursos de Pedagogia, compreendendo que a docência é apenas uma de suas práticas e que a Pedagogia, portanto, não pode ser reduzida a esta. Ou seja, a docência subordina-se a Pedagogia e não o contrário. Além disso, não se pode limitar a prática educativa apenas as ações que acontecem no sistema 
escolar, nem limitar a didática à sala de aula, já que o ato de aprender e ensinar acontece em vários lugares, que também produzem influências formativas sobre os sujeitos.

Nesse sentido, questionou-se sobre as percepções da qualidade da formação acadêmica do curso de Pedagogia, em relação a: que expectativas de atuação profissional os acadêmicos concluintes manifestam? Quais as concepções de Pedagogia? Como as experiências formativas durante o curso proporcionaram a aproximação dos concluintes com campo de atuação não escolar? Quais as demandas sociais necessárias à profissão do pedagogo? Partindo dessas problemáticas, este trabalho objetiva verificar as possibilidades que o curso de Pedagogia apresenta para a formação de pedagogos em espaços não escolares.

Compreende-se que a inserção de processos educativos nos espaços não escolares requer do curso de Pedagogia uma ampliação das práticas pedagógicas para atender às diferentes demandas, consequentemente, exige uma ressignificação da construção da identidade profissional dos pedagogos para além da sala de aula.

\section{Método}

A pesquisa segue uma abordagem qualitativa, pautando-se na interpretação do pesquisador e da pesquisadora como uma relação sistemática e ao mesmo tempo dinâmica com o objeto (SAMPIERI; COLLADO; LUCIO, 2013).

A pesquisa foi realizada junto a 20 concluintes do curso de Pedagogia, na cidade de Picos (PI). Desses, 18 mulheres e 2 homens. No que diz respeito às idades, $71 \%$ têm entre 20 a 25 anos, o restante, $29 \%$ têm mais que 25. Ao longo do texto, esses sujeitos serão identificados pelos seguintes códigos: "AC" acompanhado de um algarismo, o que representa o "Aluno concluinte" em uma determinada sequência numérica. Assim, preserva-se a identidade pessoal dos sujeitos e, ao mesmo tempo, facilita a identificação dos mesmos. Os participantes foram informados dos procedimentos éticos em conformidade com as orientações da Resolução 466/2012, do Conselho Nacional de Saúde (CNS), em que manifestaram o consentimento livre e esclarecido.

Os dados foram coletados através de um questionário estruturado com questões objetivas. Optou-se pelo uso do questionário por ser um instrumento que possibilita "traduzir os objetivos da pesquisa em questões específicas" (GIL, 2010, p. 121). Por isso, o processo de 
elaboração das questões exige particular atenção, já que as repostas estão condicionadas às perguntas, uma vez que estas devem apresentar uma linguagem clara, concreta e precisa, para não confundir os pesquisados no momento de responder as perguntas.

O método utilizado para apreciação dos questionários foi o da Análise de Conteúdo em Bardin (2011). Essa técnica visa trabalhar com as unidades de textos, formando categorias temáticas que ajudam a explorar e explicar melhor o texto resultante da transcrição dos questionários, confrontando o corpus do texto com os objetivos da pesquisa e, posteriormente, analisá-lo com base no referencial teórico construído no trabalho. Como a autora descreve, essa análise ocorre por meio de três etapas: 1) Pré-análise; 2) Exploração do Material; 3) Tratamento dos Resultados, a inferência e a interpretação (BARDIN, 2011).

Na Pré-análise ocorre a seleção e organização dos questionários, por meio da leitura flutuante das respostas, verificando se as informações estavam coerentes com o objetivo que fomenta a pesquisa.

A segunda fase, a Exploração do Material, é mais demorada e exaustiva, incidindo em operações de codificação, no caso, optou-se para a porcentagem.

$\mathrm{Na}$ terceira fase, os dados foram traduzidos e agrupados dentro das categorias temáticas que foram as seguintes: a) escolha profissional, b) concepção de pedagogia, c) formação profissional em espaços não escolares e d) atuação profissional. Essas categorias surgiram no decorrer das leituras e com a construção do referencial teórico e fundamentaram a elaboração do questionário.

Destaca-se que não existem "regras" tanto para a nomeação, quanto para a determinação de número de categorias, essas questões ficam contingentes a quantidade do corpus de dados coletados (BARDIN, 2011).

Portanto, a Análise de Conteúdo é de suma importância, pois direcionou a pesquisa, momento em que as informações adquiridas pelo pesquisador podem entrar em conflito, ou em consenso com os dados bibliográficos dos autores.

\section{Resultados}

A categoria escolha profissional revela que mais da metade dos estudantes escolheram 
o curso de Pedagogia por considerarem ter vocação para ensinar a crianças. Essa expectativa precisa ser problematizada, tendo em vista que os alunos parecem não perceber competências e/ou habilidades inerentes à prática intencional pedagógica, uma vez que "não basta "ter jeito para lidar com crianças" para dar aula nos cursos de educação infantil. Os cursos de pedagogia e licenciatura devem proporcionar uma compreensão sistematizada da educação" (ARANHA, 2006, p. 46).

Enquanto isso, 35\% dos discentes justificaram a necessidade de continuar os estudos na graduação e de ter um curso superior. Mesmo divergindo, as expectativas apontadas pelos alunos em relação à escolha do curso de Pedagogia alertam que,

não nos tornamos professores da noite para o dia, e sim fomos historicamente construindo elementos de aproximação e distanciamento da profissão, na medida em que vivenciamos situações diferenciadas que se configuram como positivas ou negativas. É nessa caminhada que vamos continuamente constituindo maneiras de ser e estar no magistério (LIMA, 2012, p. 40).

Ao longo do curso, mais especificamente nos estágios, os alunos aproximam-se da realidade da profissão. Por meio dessa experiência, muitos acabam se distanciando da graduação em Pedagogia por não se identificarem com o magistério. Portanto, o processo de formação e profissão é uma parte indispensável para os educandos construírem sua identificação com a escolha profissional.

Entre esses percentuais, 35\% justificaram ter escolhido o curso por apresentar um campo de atuação profissional amplo e permitir uma atuação diversificada, parece-nos que eles possuem conhecimento sobre a área, vendo no curso a possibilidade de atuação além da sala de aula.

Na categoria concepção de Pedagogia, percebe-se respostas bem variadas: 37\%, compreendem a Pedagogia como uma ciência que estuda a educação, destacando o teor sistemático inerente à formação do pedagogo como condição para a transformação dos sujeitos. Para Schimied-Kowarzik (1983), a Pedagogia é uma ciência prática da/e para a práxis educacional, considerando a dialeticidade do real educativo, ou seja, primeiramente, deve-se estudara prática social para depois intervir nela e transformá-la. 
Já 21\% responderam que a Pedagogia é uma metodologia de ensino. Segundo Libâneo (2005, p. 29), essa concepção parte do senso comum, quando afirmam que "a Pedagogia é o modo como se ensina o modo de ensinar a matéria, o uso de técnicas de ensino. O pedagógico aí diz respeito ao metodológico, aos procedimentos. Trata-se de uma ideia simplista e reducionista". Para esse autor, a Pedagogia estuda o fenômeno educacional na sua totalidade e ao mesmo tempo orienta e sistematiza toda ação educativa.

Ainda de acordo com os resultados, 30\% afirmaram que a Pedagogia é o curso responsável por estudar o ensino e a aprendizagem de maneira aprofundada. A definição dada a Pedagogia, ora vista como ciência da educação, ora como arte, é analisada por Franco (2008) quando destaca que a Pedagogia recebeu a definição de ser arte da educação, porque no seu caminhar científico foi influenciada, em especial, pelos psicólogos que dominavam o manuseio de instrumentos experimentais.

Para $15 \%$ dos participantes, a Pedagogia é compreendida como uma área de grande abrangência profissional, remetendo-nos à diversidade de práticas pedagógico-sociais que acontece para além da sala de aula, ou seja, nos espaços não escolares. Entende-se que a Educação Não Escolar corresponde ao conjunto de ações ou experiências educativas que ocorrem fora da escola, podem conter uma organização didática ou não, vai depender do tipo de prática desenvolvida, já que educação no/do campo social é ampla e varia de acordo com o espaço (DIAS, 2020).

Percebe-se, entre os concluintes, que não há uma clareza sobre a concepção de Pedagogia, ora entendida como metodologia de ensino, ora como didática, ora como curso de formação, ou ainda, como ciência da educação, área que ultrapassa os muros da escola. Porém, os graduandos necessitam ter clareza sobre a concepção de Pedagogia como Ciência da Educação que deve estar comprometida em estudar a educação no seu sentido global, e não apenas com a escolarização nos ambientes formais de ensino.

A categoria formação profissional em espaços não escolares evidenciou que o curso de Pedagogia forma os pedagogos para atuarem na Educação Infantil e nos Anos Iniciais do Ensino Fundamental,. cenário revelado pelas respostas dos discentes da pesquisa: "só aprofunda os conhecimentos da área da docência, não dando enfoque aos outros campos de atuação do pedagogo" (AC 1); "Não corresponde a minhas expectativas, porque o curso só se restringe à sala de aula, não nos prepara para atuar em outros espaços" (AC 4); "Não, porque há muita repetição de conteúdos em cada período e o curso não nos prepara para atuarmos em 
espaços não escolares." (AC 5).

No entanto, antes de iniciarem a graduação, muitos alunos tinham expectativas de trabalharem em espaços não escolares. Todavia, pelos relatos, nota-se que o curso de Pedagogia tem como base a docência e não proporciona o preparo esperado por alguns graduandos que almejavam trabalhar em espaços educativos diversos. Ressaltaram, ainda, problemas de organização curricular quando afirmaram que as disciplinas são repetitivas. Porém, $40 \%$ dos alunos participantes da pesquisa estão satisfeitos com a formação, conforme destacaram: "porque o curso proporciona uma formação política e social” (AC 6); "Sim, principalmente, em relação ao nível de criticidade de teorias, conceitos que tivemos acesso, ou seja, Pedagogia não é um curso fácil" (AC 7); "Sim, porque o curso tem me preparado muito bem para ensinar as crianças da educação básica" (AC 10). Isso é muito importante, porque profissionais qualificados podem desenvolver um bom trabalho pedagógico. Quando há identificação com o campo profissional, logo é refletido no seu trabalho, pois as ações são exercidas com prazer, porém, quando acontece o contrário, esse campo poderá ser comprometido.

Outros 20\% responderam que suas expectativas foram atingidas em parte, justificando-se por ser um "curso bom, porém muito longo, com disciplinas repetitivas, devendo focar no que realmente é necessário, que são as experiências escolares na gestão e docência" (AC 8). "Em parte, devido à falta de preparo de alguns professores e das disciplinas repetitivas".

Nessa categoria, um dos alunos justificou a ausência de profissionalismo de alguns docentes, apesar de não detalhar em que aspectos deixaram a desejar. Cabe refletir sobre as competências que devem ser desenvolvidas pelos educadores. Sobre isso, Rios (1997) define o "saber fazer bem como sinônimo de competência, em princípio, aproxima-se da posição de muitos educadores que apresentam esse saber fazer bem em uma dupla dimensão: técnica e política" (RIOS, 1997, p. 51). O docente necessita da técnica, ou seja, domínio de conteúdo para executar seu papel dentro da sala de aula e socialmente, mas isso não é suficiente, é necessário uma ligação com o aspecto político à direção do saber que deve contribuir para a transformação social dos educandos. Assim, saber fazer bem implica na capacidade do professor refletir sobre sua ação de maneira crítica, tornando-se um profissional competente.

$\mathrm{Na}$ categoria de atuação profissional em espaços não escolares. Obteve-se os seguintes resultados: $70 \%$ dos participantes responderam que não adquiriram nenhuma 
experiência no espaço não-escolar, mas $30 \%$ dos alunos, citaram as seguintes experiências: "tive a oportunidade de atuar em uma brinquedoteca, que me possibilitou trabalhar com o lúdico, fazendo relação com o espaço escolar" (AC 9); "Durante o curso, pude trabalhar como monitora na brinquedoteca do Hospital Regional, até que o projeto encerrou por conta da reforma do hospital" (AC 10); "Destaco como significativa a minha experiência como professora da escola dominical da Igreja na qual frequento" (AC 11); "As atividades nãocurriculares (obrigadas pelo curso), projeto de extensão, palestras, congressos” (AC 17); “Considero uma experiência significativa a oportunidade de aplicar o projeto Sarau Literário e Musical no abrigo dos idosos, onde a emoção foi impossível de controlar" (AC 20).

Tais alunos consideram essas vivências como sendo espaço de formação acadêmica e realmente são. Nota-se que as ações educativas aconteceram em diferentes contextos educativos, ainda que não tivessem conhecimentos teóricos que fundamentassem essas práticas.

Perguntou-se sobre quais demandas sociais tornam necessária a profissão do pedagogo no contexto atual. As respostas apontam que a maioria dos concluintes reconhece a existência de demandas para a atuação do pedagogo em outros espaços além da escola, citando espaços diferenciados como os hospitais (36\%), sistema penitenciário (13\%), e ainda, 33\% mencionaram comunidades rurais, sertanejas, indígenas, quilombolas e periféricas, postos de saúde, empresas, redutos religiosos e etc. Portanto, "não cabe mais uma visão empobrecida dos estudos pedagógicos, restringindo-os aos ingredientes de formação de licenciados" (LIBÂNEO, 2005, p. 40). Não se trata de desvalorização da docência, mas da valorização da atividade pedagógica em sentido mais amplo, no qual o docente está incluído.

Sabe-se que ainda há muitas indefinições em relação ao campo de atuação do pedagogo e o maior desafio está em como preparar esse profissional para atender a tais demandas. Essas novas expectativas e possibilidades de atuação do pedagogo exigem uma mudança na formação dos educadores que irão atuar nesses contextos.

Sobre a percepção da qualidade da formação acadêmica no curso de Pedagogia, até o presente momento, em relação à identidade do pedagogo, 65\% responderam como sendo boa, "porque já me vejo uma profissional apta a contribuir na formação de determinados indivíduos" (AC 10); outro afirmou: "porque a Pedagogia tem ganhado lugar em vários espaços e teoricamente compreendemos isso, mas o curso nos prepara para a sala de aula" (AC 17). 
Por outro lado, 30\% consideram apenas razoável, porque "o curso de Pedagogia deveria possibilitar atuar em outros espaços não escolares, no entanto, o nosso curso nos prepara para atuarmos na sala de aula" (AC 4). "Compreendo a identidade do pedagogo como sujeito que trabalha/pesquisa a educação em todos os ambientes (AC 2)". Os demais, 5\%, justificam que "A formação na academia possui o foco na educação formal; desse modo, forma o docente para dar aula na escola, não existe discussões nem disciplina que abordem a educação em espaços não escolares" (AC 1).

Os resultados confirmam a hipótese levantada neste estudo, a qual o curso tem a docência como eixo principal. No entanto, a Pedagogia é uma ciência muito mais ampla, deve atender a uma prática educativa social que ultrapassa a sala de aula. Todavia, quando questionados sobre a qualidade da sua formação acadêmica em relação à aquisição de conhecimentos e habilidades profissionais necessárias à prática do pedagogo em espaços não escolares, identifica-se uma limitação em relação aos conhecimentos construídos e experiências vivenciadas nesses espaços.

Nessa perspectiva, $57 \%$ definiram como ruim a qualidade de seus processos formativos, justificando que "o curso só aborda superficialmente sobre a atuação, mas não oferece conhecimentos práticos para esses espaços" (AC 12). "O curso basicamente é centrado para lecionar” (AC 13). “O curso não nos dá suporte necessário em relação à atuação em espaços não-escolares" (AC 14). "Tem um pouco de teoria, e prática, de jeito nenhum" (AC 15). "Não recordo terem trabalhado essa temática" (AC 16). Os outros 38\% que definiram como razoável, deram justificativas semelhantes: "a nossa formação não nos prepara para atuar em espaços não-escolares, mas apenas para dar aula na escola" (AC 17). "O curso de Pedagogia pouco contempla as atividades em espaços não-escolares" (AC 18). Apenas $10 \%$ definiu como boa, já que "proporcionou uma visita ao abrigo dos idosos, onde foi emocionante e notei que é necessário desenvolver práticas pedagógicas nesse local” (AC 19).

[...] o curso de Pedagogia deve formar profissionais da educação com novos perfis, capazes, por exemplo, de atuar com as novas tecnologias, com as diferentes mídias e linguagens, com participação social, com o lazer, com programas de inclusão dos culturalmente diversos, dos portadores de necessidade especiais, e outras inúmeras possibilidades formativas que a vida 
social e produtiva tem demandado em decorrência do regime de acumulação flexível (KUENZER,2006, p.190).

Assim, as novas demandas do mundo de trabalho exigem novas adequações profissionais para exercer uma prática social educativa e pedagógica, abrindo a possibilidade de qualificar o pedagogo para tais práticas, já que o fundamento da Pedagogia é o fenômeno educativo na sua complexidade e extensão social, sendo a docência uma de suas atividades pedagógicas, mas não o eixo central da disciplina, por isso o currículo deve priorizar conhecimentos teóricos e metodológicos do campo educacional em contextos escolares e não escolares. Desse modo, após a análise detalhada e geral dos questionários, foi possível chegar à conclusão que não há nenhuma disciplina voltada para o espaço não escolar, ou seja, o curso tem como base a docência o que gera uma insatisfação para os estudantes que almejam trabalhar nos espaços não escolares.

\section{Considerações finais}

Este trabalho expôs uma reflexão sobre as expectativas profissionais e as percepções dos concluintes do curso em Pedagogia sobre a formação para atuação do pedagogo em espaços não escolares. Percebe-se que as expectativas dos concluintes, em sua maioria, não está sendo correspondida, estes apontam várias causas, tais como: disciplinas repetidas, centralizadas nos conhecimentos da área da docência; falta de profundidade em fundamentos da atuação do pedagogo nos espaços não escolares; e, a dissociação entre teoria e prática percebida durante o estágio.

Embora nem todos os concluintes pesquisados tenham se sentido contemplados durante o curso de pedagogia em relação às expectativas voltadas para a formação em espaços não escolares, $40 \%$ demonstraram satisfação com a formação proporcionada pela graduação, tendo em vista que o curso permite uma formação política e social. Esses mesmos alunos desmitificam, ainda, a ideia de que a Pedagogia é fácil, pois conforme relataram, essa formação exige domínios de várias teorias para fundamentação das práticas educativas na sala de aula. 
Evidenciou-se que os alunos participantes da pesquisa, citaram algumas experiências vivenciadas no decorrer do curso em espaços não escolares como: hospitais, sistema penitenciário e atividades não-curriculares (obrigatórias na composição curricular do curso). Porém, ressaltaram que sentiram falta de estudos com abordagens relativas aos conhecimentos teóricos e metodológicos para fundamentação de suas ações em ambientes semelhantes aos mencionados. Destacaram que há demandas para atuação de pedagogos nesses e em outros espaços não escolares, o que requer novos perfis profissionais que possam contribuir para uma formação humana e crítica dos educandos, seja na escola ou em novos cenários educativos.

Ao longo do estudo, defende-se uma concepção ampla de Pedagogia, já que há muitas práticas educativas que acontecem em diversos contextos sociais. Sendo assim, a Pedagogia não pode ser resumida apenas à sala de aula. Sabe-se que os processos educacionais estão cada vez mais complexos e demandam uma ciência que transforme essa complexidade, sendo necessário um saber pedagógico amplo e específico. Dessa forma, não podemos reduzir o objeto da Pedagogia, que é a prática educativa, apenas à sala de aula, já que essas práticas podem ser inseridas em contextos não-escolares. Por isso, é preciso que o pedagogo seja mais que um docente, seja um cientista que está preocupado não apenas em investigar a realidade educacional, mas em transformá-la.

Verifica-se que a identidade profissional dos pedagogos precisa ser estruturada para atender aos desafios do campo não escolar, já que, quando essa identidade não está claramente concebida, é possível uma atuação pautada em práticas improvisadas ou em reprodução da forma escolar para outros espaços, sem uma reflexão crítica e coerente com a realidade.

Enfim, espera-se, com esta pesquisa, mostrar um novo olhar para a formação do pedagogo do curso de Pedagogia. Não se pretende criticar o curso ou fornecer respostas definitivas, mas gerar novas reflexões em torno de melhorias e mudanças para que o pedagogo realize uma prática social sistematizada e verdadeiramente comprometida com a emancipação dos sujeitos nos espaços escolares e não escolares.

\section{Referências}

Revista Devir Educação, Lavras, vol.4, n.2, p.328-342 jul./dez., 2020. 
BARDIN, Laurence. Análise de conteúdo. 70 ed. Lisboa: Portugal, 2011.

BRASIL. Ministério da Educação. Conselho Nacional de Educação. Diretrizes Curriculares nacionais para o curso de Graduação em Pedagogia. Resolução n ${ }^{\circ} 1$ de 15 de maio de 2006. Brasília: MEC, 2006.

DIAS, Luciana Silva. Processos de planejamento didático em Educação Social: significados e estratégias. 2020. 137 p. Dissertação (mestrado em educação), Universidade Federal da Paraíba, João Pessoa, 2020.

FRANCO, Maria Amélia Santoro. Pedagogia como ciência da educação. 2 ed. São Paulo: Cortez, 2008.

FREIRE, Paulo. Pedagogia do Oprimido. 17 ed. Rio de Janeiro, Paz e Terra, 1987.

GIL, Antônio Carlos. Métodos e técnicas de pesquisa social. 6 ed. São Paulo: Atlas, 2010.

KUENZER, Acácia Zenaída. As diretrizes Curriculares para o curso de Pedagogia: uma expressão da epistemologia da prática. XIII ENDIPE. Anais. ISBN: 85-373-0079-9. Recife: Bagaço, 2006.

LIMA, Maria Socorro Lucena. A hora da prática: reflexões sobre o estágio supervisionado e ação docente. 2. Ed. Fortaleza: Edições Demócrito Rocha, 2001.

LIBÂNEO, José Carlos. Pedagogia e pedagogos, para quê? 8 ed. São Paulo: Cortez, 2005.

LIBÂNEO, José Carlos. PIMENTA, Selma Garrido. Formação de profissionais da educação: visão crítica e perspectivas de mudança. In: PIMENTA, Selma Garrido (Org.) Pedagogia e pedagogos: caminhos e perspectivas. São Paulo: Cortez, 2002.

PÉREZ SERRANO, Gloria. Investigación cualitativa: retos e interrogantes. 5 ed. La Muralla, 2011, p. 133-157.

PIMENTA, Selma Garrido. Pedagogia e pedagogos: caminhos e perspectivas. São Paulo: Cortez, 2011. p. 155- 197.

RICHARDSON, Roberto Jarry. Métodos e técnicas. 3.ed. São Paulo: Atlas, 1999.

RIOS, Terezinha Azeredo. Ética e Competência. $5^{a}$ ed. São Paulo: Cortez, 1997. p. 45-67.

SCHIMIED-KOWARZIK, Wolfdietrich. Pedagogia Dialética. São Paulo: Brasiliense, 1983.

SHIMITZ, Taís. O pedagogo e a educação contemporânea: muitos desafios. Curitiba: Intersaberes, 2013. 
SAMPIERI, Roberto Hernandez; COLLADO, Carlos Fernández; LUCIO, María del Pilar Baptista. Metodología de la investigación. 3. ed. México: McGraw Hill, 2010.

SEVERO, José Leonardo Rolim de Lima. A significação da Pedagogia: discurso curricular, representações sociais e perspectivas de ensino na formação inicial de pedagogos. Dissertação (Mestrado em Educação) Universidade Federal da Paraíba. João Pessoa, 2012. Disponível em: http://tede.biblioteca.ufpb.br/bitstream/tede/4667/1/arquivototal.pdf. Acesso em: 06 jun.2019.

SEVERO, José Leonardo Rolim de Lima. Educação não escolar como campo de práticas pedagógicas. Revista Brasileira Estudos Pedagógicos. Brasília, v. 96, n. 244, p. 561-576, set./dez. 2015.

Disponível:

http://www.scielo.br/scielo.php?pid=S217666812015000300561\&script=sci_abstract\&tlng=p t. Acesso em: 22 set.2019.

SEVERO, José Leonardo Rolim de Lima. Marcos regulatório das políticas curriculares do curso de pedagogia no Brasil (1939-2006): tramas históricas da (des)configuração da pedagogia. In: IX Seminário nacional de estudos e pesquisas "história, sociedade e educação no Brasil” Universidade Federal da Paraíba. João Pessoa, 2012 Disponível: http://www.histedbr.fe.unicamp.br/acer histedbr/seminario/seminario9/PDFs/2.22.pdf. Acesso em: 22 abril.2019.

Recebido em 05/09/2020

Aprovado em 30/10/2020 